Portland State University

PDXScholar

\title{
The Oregon Mental Health Referral Checklists: Concept Mapping the Mental Health Needs of Youth in the Juvenile Justice System
}

Kevin Corcoran

Portland State University

Follow this and additional works at: https://pdxscholar.library.pdx.edu/socwork_fac

Part of the Social Work Commons

Let us know how access to this document benefits you.

\section{Citation Details}

The Oregon Mental Health Referral Checklist: Concept mapping the mental health needs of youth in the juvenile justice system. Brief Treatment and Crisis Intervention, 5(10), 9-18.

This Article is brought to you for free and open access. It has been accepted for inclusion in School of Social Work Faculty Publications and Presentations by an authorized administrator of PDXScholar. Please contact us if we can make this document more accessible: pdxscholar@pdx.edu. 


\title{
The Oregon Mental Health Referral Checklists: Concept Mapping the Mental Health Needs of Youth in the Juvenile Justice System
}

\author{
Kevin Corcoran, PhD, JD
}

\begin{abstract}
This article summarizes the development of checklists to identify the mental health needs of youth in the juvenile justice system. With concept mapping as its base, a 31-item checklist was developed in three parallel forms and assessed on three samples: youth in a locked correctional facility and parents and juvenile justice professionals of adjudicate youth who were sentenced to community service. The instruments appear to have acceptable to very good internal consistency and moderate to strong coefficients of equivalence. Total symptoms were associated with internal and external problems for youth, suggestions from a trusted friend that one might have a mental health problem, and various other mental health history variables for the youth version. The instruments appear to have acceptable to very good reliability and very good validity for the youth version; furthermore, they are useful in identifying acting-out crises and psychological crises, including harm to self, others, and property. [Brief Treatment and Crisis Intervention 5:9-18 (2005)]
\end{abstract}

KEY WORDS: adolescent mental health, juvenile justice, measurement tools.

\section{The Oregon Mental Health Referral} Checklists: Identifying the Mental Health Needs of Youth in the Juvenile Justice System

Practitioners in adolescent mental health and juvenile justice voice a need for a rapid assessment tool to identify the mental health needs of

From the Graduate School of Social Work at Portland State University.

Contact author: Kevin Corcoran, PhD, JD, Professor of Social Work, Portland State University, Graduate School of Social Work, Portland, Oregon 9720. E-mail: mypalkevin@aol.com.

doi:10.1093/brief-treatment/mhi003 adolescents. This is especially the case in juvenile justice settings, where behavioral problems are common and considerably more severe than clinical samples or samples from the general population (Achenbach, 1997; Cocozza, 1992). Concomitant with the mental health problems, youth in the juvenile justice system face a disproportionate number of crises, especially when first incarcerated or initiated into gang violence. Some crises common to youth in the justice system include harm to self, others, and property; psychotic symptomatology; running away; depression; and emotional labiality, including angry outbursts.

Such an assessment tool should be available in three parallel forms for use by different

Brief Treatment and Crisis Intervention Vol. 5 No. 1, (c) Oxford University Press 2005; all rights reserved. 
sources for observing mental health symptomatology. The three sources of assessment should include self-observations by the youth and observations of the youth by the youths' parents and by professional staff members working with the youth. The reasons for these three sources of observations are that, one, some symptoms are best observed by the youth, such as affect or hallucinations; two, parents are a viable source, as they are likely to observe sudden or gradual behavioral changes in their child, even if subtle; and, three, professional staff members, of course, are a viable source for observations by way of mental status exams, clinical interventions, and evaluations of a client's progress in treatment. This article reviews the development and initial psychometrics of a 31-item checklist for use by youth, parents, and professional staff. The instruments are reprinted in the appendix.

\section{Methodology}

\section{Instrument Development}

The Oregon Mental Health Referral Checklist (OMHRC) was developed with a panel of 15 administrators and providers in mental health and juvenile justice. ${ }^{1}$ The administrators comprised program directors and assistant directors from Oregon's mental health, juvenile justice, and children and family agencies. Among the providers were clinical social workers, probation officers, court counselors, and one child psychiatrist. The panel first generated a list of symptoms $(N=84)$ considered "typical" or "characteristic" of youth in the juvenile justice system; 16 were removed because they were

\footnotetext{
${ }^{1}$ The parallel forms of the OMHRC are not in the stream of commerce and are not intended for commercial sale. The OMHRCs are in the public domain and may be copied ad libitum.
}

judged to be unobservable (e.g, a head injury) or were not relevant to mental health (e.g, hearing and vision problems).

The resulting 68 symptoms were then analyzed using concept mapping (CM), a statistical package including multidimensional scaling and cluster analysis (Trochim, 1989). CM is a quantitative process that facilitates the description of any idea or topic and then represents the idea in the form of a third-dimensional map. The procedures typically require the participants to brainstorm a set of statements or concepts; in this case, it was mental health symptoms of youth in the juvenile justice system. Participants then sort the statements or concepts into distinguishable groups and rate each on a relevant scale; in this case, it was a triage rating of the immediacy of needing a mental health referral, with scores ranging from 1 (no need) to 5 (immediate need).

These data were analyzed first with twodimensional multidimensional scaling (MDS), which constructs a symmetric matrix of similarities by scoring items sorted into the same group as 1 and items in different groupings as 0 . Scores are then summed across the number of raters for a total score, with the similarity matrix analyzed using nonmetric MDS analysis with a two-dimensional solution (Weller \& Romney, 1988). The symptoms are then displayed on a two-dimensional space with more similar symptoms located closer together and with those less similar further apart.

The results of MDS configuration are then analyzed with hierarchical cluster analysis, and the average triage rating for each symptom is computed using Ward's algorithm (Everitt, 1980). The cluster analytic procedure, essentially, takes the MDS configuration of the symptoms and partitions them into nonoverlapping and distinguishable clusters. The average rating of each symptom is then calculated, and the results produce a three-dimensional map displaying the average ratings for all 
symptoms and the averages for the separate clusters based on the symptoms in each cluster.

In summary, the CM procedure first displays each symptom on the two-dimensional plan, with similar symptoms located closer together than dissimilar ones. The distribution of symptoms is then analyzed with hierarchical cluster analysis to form distinguishable groupings. The ratings of each symptom on the 5-point triage scale are then averaged for the symptoms in the cluster, with the average rating forming the three-dimensional cluster map.

\section{Results}

Of the 68 mental health symptoms initially generated by the panel, the results of the MDS provide a point map with 11 meaningful clusters (Figure 1). For purposes of identifying youth in the juvenile justice that need mental health services, a 12-cluster solution was not meaningful as it simply distinguished a subset within the antisocial/conduct cluster. This distinction was not likely to facilitate referrals for mental health treatment as the symptoms were generally low on triage scores. Figure 2 illustrates the average triage rating for each cluster and the average of each symptom within the separate clusters.

The validity of the triage rating was estimated by comparing the scores from 15 members of the panel with the child psychiatrist's scores. It was asserted that a child psychiatrist's scores would form an appropriate comparison because of one's education, training, and specialized credentialing. The ratings of triage were extremely correlated $(r=.95)$, indicating that there was $90 \%$ commonality between the scores by administrators and providers with the standard of the child psychiatrist. This finding suggests that administrators and providers in the juvenile justice and mental health systems are very good at recognizing the triage needs of specific mental health symptoms.

The CM results are particularly meaningful for identifying mental health needs of youth in the juvenile justice system, as the distance between problems reflect symptoms germane to mental health in contrast to those germane to the juvenile justice system. The cluster at the far right of the plain in Figure 2 reflects social skill deficits, which have very low triage ratings; in contrast, the cluster at the far left reflects suicidality, which has high triage ratings. Symptoms more germane to the mental health system are distributed on the left of the map, with those of the juvenile justice system on the right-hand side. Additionally, the results are divisible on two dimensions: one ranging from internal symptoms at the top of the map (e.g., depression) to external symptoms at the bottom (e.g., tortures animals, destroys property). Symptoms in the antisocial/conduct cluster and social skills problems had low triage ratings and were not considered as those suggesting a mental health referral. All items were dropped from the instrument, except for the item angry/argues excessively, which was included but had the lowest of all the triage rating.

Item reduction for the final OMHRC was based on selecting those symptoms with high triage ratings within each mental health condition. Thirty-eight items survived this procedure, with the average triage rating being 2.8 or higher. This resulted in the 38-item OMHRC prototype, which was formatted as a checklist for use as a self-report by the youth or as a report of the youth by a parent or professional staff member. Scores are the total number of symptoms, although the need for a mental health referral may exist due to a single symptom, such as suicide, bizarre behavior, or hallucinations. Items are organized in descending order of triage ratings and are grouped in the CM categories, which allow for Guttman scaling. 


\section{Cluster Map of Symptoms/Problems}

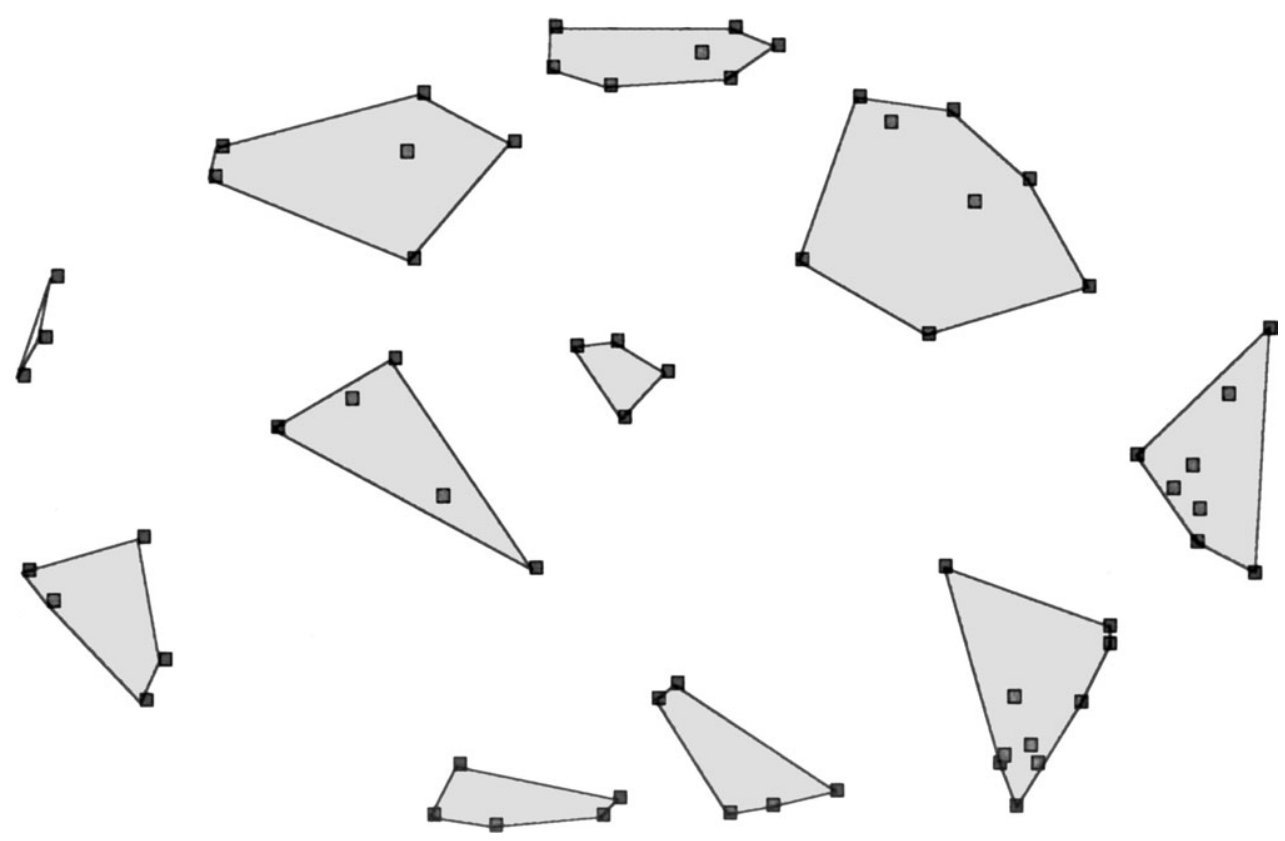

FIGURE 1

Point map of symptoms/problems.

\section{Psychometric Analysis}

\section{Procedures and Participants}

There were three samples in this study. In sum, 146 youths who were adjudicated and sentenced to community service were evaluated on the 38-item OMHRC-staff version by court counselors and probation officers. The youth were from two rural counties (one in eastern Oregon and the other on the coastal range) and a large urban county. In addition, parents from one rural county completed the OMHRC-parent version: 52 parents of rural youth completed the instrument in usable form. The youth concurrently completed the Child Behavior Checklist (Auchenbach, 1997) and other measures, such as mental health history and suicidal behaviors. A third sample consisted of 83 incarcerated youth in the Oregon Youth Authority. These youth completed the final youth version of the OMHRC with the instruments noted above. The community service youth were remunerated $\$ 10$ or 1 hour credit toward their sentence in consideration for completing the instruments, whereas the incarcerated youth were remunerated a $\$ 2$ value in a group activity, as possession of money was prohibited in the prison.

\section{Results}

Estimates of reliability of the 38 items derived from the concept mapping were assessed for internal consistency. Thirty-one items produced the highest reliability coefficients at $.91, .72$ and, .92 for the parent, staff, and youth versions, respectively. As parallel forms with the parent and staff versions, youth version scores had very good coefficients of equivalence-.51, $p<.01$, and .69, $p<.01$, respectively - but there was only moderate equivalence between the parent and staff versions, .36, $p<.05$. 
Symptom Triage Rating

$1=1.71-2.31$

$2=2.32-2.90$

$3=2.91-3.50$

$4=3.51-4.10$

$5=4.11-4.70$

\section{Internal symptoms/problems}

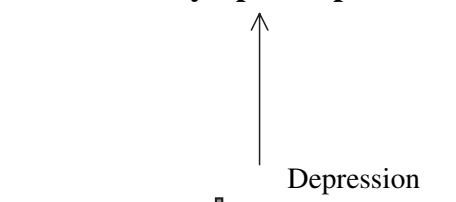

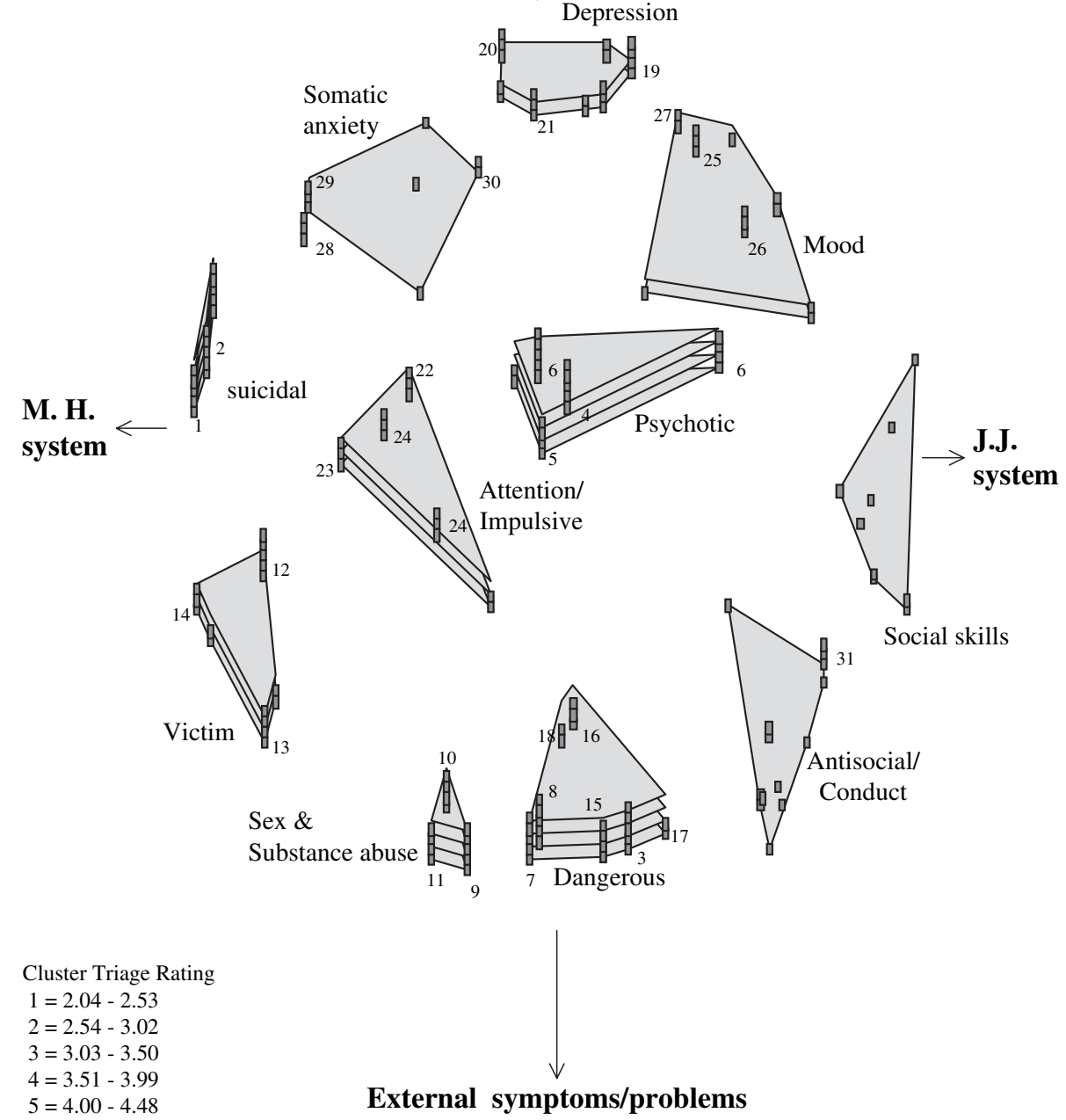

FIGURE 2

Three-dimensional cluster map.

The validity of the 31-item OMHRCs for all three samples was estimated first with knowngroups procedures. Based on the youth's response to the dichotomous item "Has anyone you trust ever suggested that you might have an emotional or mental problem?" youth responding yes were compared to those endorsing no. The former were considered to have higher mental health needs than the latter.
For the parent version, youth saying yes had an average OMHRC score of $19.4(S D=8.4)$, while those saying no had an average score of $12.6(S D=9.0)$, which was significantly different, $t=2.7, p<.05$. The staff version scores were also distinguished by this variable $(M=16.6, S D=9.5 ; M=13.4, S D=6.9$, for yes and no groups, respectively; $t=2.1, p<.05$ ). For the incarcerated youth, the results for this 
TABLE 1. Known-Groups Validity for Low and High Mental Needs on OMHRC-Youth Version

\begin{tabular}{|c|c|c|c|c|c|c|}
\hline & \multicolumn{2}{|c|}{ No, low need } & \multicolumn{2}{|c|}{ Yes, high need } & \multicolumn{2}{|c|}{$t$ test } \\
\hline & $M$ & $S D$ & $M$ & $S D$ & $t$ & $p$ \\
\hline $\begin{array}{l}\text { Trusted other } \\
\text { recommended treatment }\end{array}$ & 7.2 & 5.7 & 12.4 & 8.3 & 3.1 & .01 \\
\hline $\begin{array}{l}\text { Have seen mental } \\
\text { health professional }\end{array}$ & 7.5 & 5.2 & 9.2 & 9.2 & 3.7 & .01 \\
\hline $\begin{array}{l}\text { Need to see mental health } \\
\text { professional now }\end{array}$ & 7.8 & 5.3 & 13.8 & 9.0 & 3.6 & .01 \\
\hline Suicidal ideations & 5.9 & 4.3 & 15.6 & 7.5 & 6.8 & .00 \\
\hline Suicidal plan & 10.2 & 7.9 & 16.2 & 7.3 & 2.8 & .01 \\
\hline
\end{tabular}

procedure, with four others criteria, were significant and are displayed in Table 1 . The results support the assertion that total OMHRC scores distinguish youth with more mental health needs from those with fewer needs.

Concurrent validity was estimated by correlating OMHRC scores with internal and external problems scores of the Achenbach's (1997) Child Behavior Checklist. The parent version correlated significantly only with external problem scores $(r=.49, p<.05)$ and were not significant for internal or external measures with the staff version. The youth version, however, had good concurrent validity coefficients, correlating with internal problem scores $(r=$ $.67)$ and externality problem scores $(r=.65)$, significant at the .01 level. These findings suggest that parents are able to make somewhat accurate observations of external mental health problems needing mental health referrals, whereas the better source of assessment originates from the youth, who is accurate in observing symptoms associated with internal and external problems.

\section{Summary and Limitations}

The results of the concept mapping and the psychometric estimates suggest that the OMHRC is an acceptable tool to assess the mental health needs of youth in the juvenile justice system. It seems that administrators and providers are about $90 \%$ as accurate as a child psychiatrist is in triaging symptoms but are not accurate in observing internal or external mental health symptoms. The assessment has been based on total symptomatology, yet all three instruments may identify a mental health need from a single item (e.g., hallucinations or suicide). As indexes of mental health symptoms, the OMHRC is particularly useful in identifying crises common to youth entering the juvenile justice system for the first time, whether first arrest or first incarceration.

This study is not without limitations, of course. First and foremost, the sample sizes were not huge. Therefore, generalizing too widely is unwarranted. Additionally, the staff version was restricted to court counselors and probation officers, who may not be the most keenly trained professionals in recognizing the mental health symptoms of youth. It remains to be seen if the instrument is psychometrically sound with mental health professionals, school personnel, or other professionals. In spite of these shortcomings, the initial results suggest that the three versions of the OMHRC are consistent instruments to identify mental health symptoms of youngsters. The most accurate observations are limited to parents observing external problems, whereas youth are accurate in observing internal and external symptoms. 


\section{Appendix: Three Versions of the OMHR Checklist}

\section{OMHR CHECKLIST - YOUTH VERSION}

What is your name?
How old are you?
What agency gave
you this form?
What is your
medical card \#?

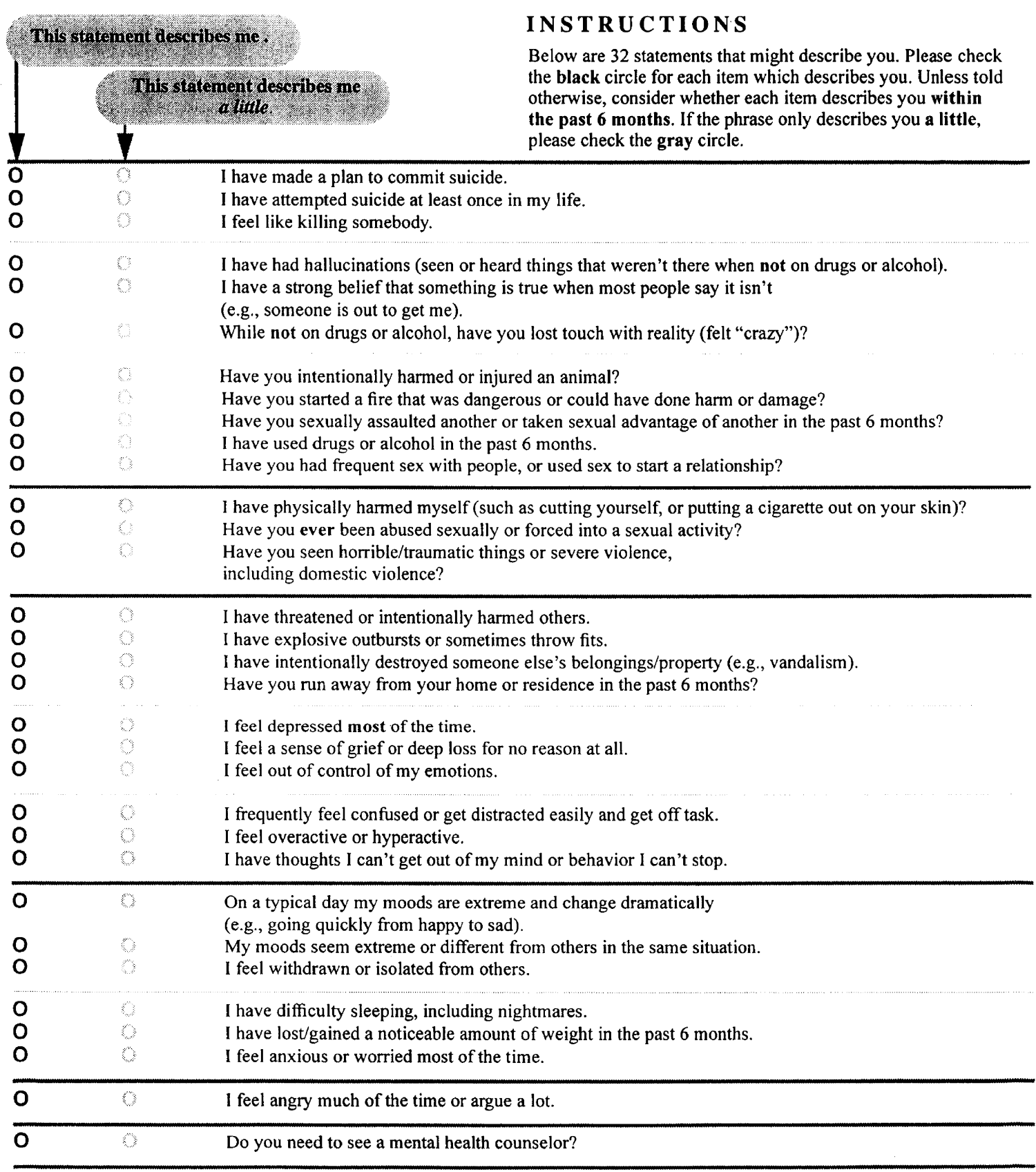

What is today's date?

What is your race?

Who do you typically

see at that agency?

What is your case \#? the past 6 months. If the phrase only describes you a little, please check the gray circle.

Please return this to the juvenile justice counselor or mental health counselor, unless told otherwise. 


\section{OMHR CHECKLIST - PARENT VERSION}

Child's name
Child's age
What agency gave
you this form?
What is the child's
medical card $\#$ ?

Thav or ain fath s certain this: item describes this vouth.
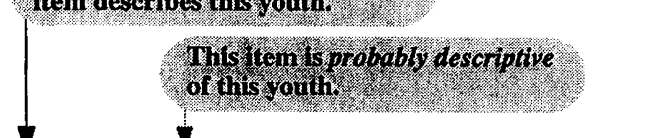

\author{
What is today's date? \\ Race \\ Who is your contact \\ person at that agency? \\ What is your relationship with \\ the youth? (please specify)
}

\section{NS T RUCTIONS}

Below are 32 behaviors you may have observed with this child. Please check the black circle for each item which you know or are fairly certain describes this youth. Unless told otherwise, consider the youth within the past 6 months. If you have your suspicions or a hunch that an item describes this child, then please check the gray circle.

\begin{tabular}{lll}
\hline $\mathbf{O}$ & \multicolumn{1}{c}{ child, then please check the gray circle. } \\
\hline & He/she seems actively suicidal/suicide risk. \\
O & Has this youth ever made a suicide attempt? \\
& The child expresses a desire to kill another person(s).
\end{tabular}

$\begin{array}{ll}\text { O } & \text { He/she appears to have hallucinations (acts as if see or hear things when not on drugs or alcohol). } \\ \text { The child expresses bizarre ideas/strong beliefs that are not true (e.g., someone is out to get him/her). } \\ \text { While not on drugs or alcohol, this child seems out of touch with reality/incoherent }\end{array}$

\begin{tabular}{ll}
\hline 0 & Physically harmed him/herself (such as cutting self with razor or burn self with cigarette). \\
O & Has this child ever been sexually abused or forced into a sexual activity? \\
Has he/she ever witnessed a traumatic event or severe violence (e.g. domestic violence)?
\end{tabular}

\begin{tabular}{|c|c|c|}
\hline $\begin{array}{l}0 \\
0 \\
0 \\
0\end{array}$ & 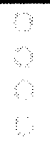 & $\begin{array}{l}\text { He/she threatens others or has intentionally harmed others in the past } 6 \text { months. } \\
\text { Has explosive outbursts/throw fits. } \\
\text { Intentionally destroyed property. } \\
\text { Frequently runs away from home. }\end{array}$ \\
\hline $\begin{array}{l}0 \\
0 \\
0\end{array}$ & 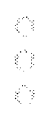 & $\begin{array}{l}\text { Has seemed depressed most of the time in the past } 6 \text { months. } \\
\text { Expresses grief/loss for no reason. } \\
\text { Has seemed out of control of his or her emotions in the past } 6 \text { months. }\end{array}$ \\
\hline $\begin{array}{l}0 \\
0 \\
0\end{array}$ & ? & $\begin{array}{l}\text { Seems frequently confused. } \\
\text { He or she is overactive or hyperactive. } \\
\text { Has had repetitive thoughts or repetitive behaviors. }\end{array}$ \\
\hline $\begin{array}{l}0 \\
0 \\
0\end{array}$ & ? & $\begin{array}{l}\text { He/she has had dramatic mood swings. } \\
\text { His/her moods have been inappropriate (e.g. extreme or different from others in the same situation). } \\
\text { This child has been detached or withdrawn. }\end{array}$ \\
\hline $\begin{array}{l}0 \\
0 \\
0\end{array}$ & 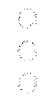 & $\begin{array}{l}\mathrm{He} / \text { she is having difficulty sleeping (too much or too little). } \\
\text { l've observed noticeable weight gain or weight loss. } \\
\text { He/she has been very anxious/nervous or worries most of the time. }\end{array}$ \\
\hline $\mathbf{O}$ & e & $\mathrm{He} /$ she is angry or has argued excessively during the past 6 months \\
\hline 0 & 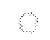 & In your opinion, does this youth need to see a mental health counselor? \\
\hline
\end{tabular}

Please return this to the juvenile justice counselor or mental health counselor, unless told otherwise. 


\section{OMHR CHECKLIST - STAFF VERSION}

Youth's Name
Age
Initiating Agency
Medical Card \#

IN S T RU CTIONS

Below are 32 problems or symptoms descriptive of youth who might need a mental health referral. Please check the black circle for each item which you know or are fairly certain describes this youth. If you have a suspicion or hunch that an item is probably descriptive, then please check the gray circle.

Actively suicidal/suicide risk Any prior suicide attempts

The child has desire to kill another person(s)

Appears to have hallucinations Expresses bizarre ideas or delusional Out of touch with reality/incoherent while not on drugs or alcohol

Intentionally harms or injures animals

Fire setter

Sexually offends

Substance abuse

Sexually acts out

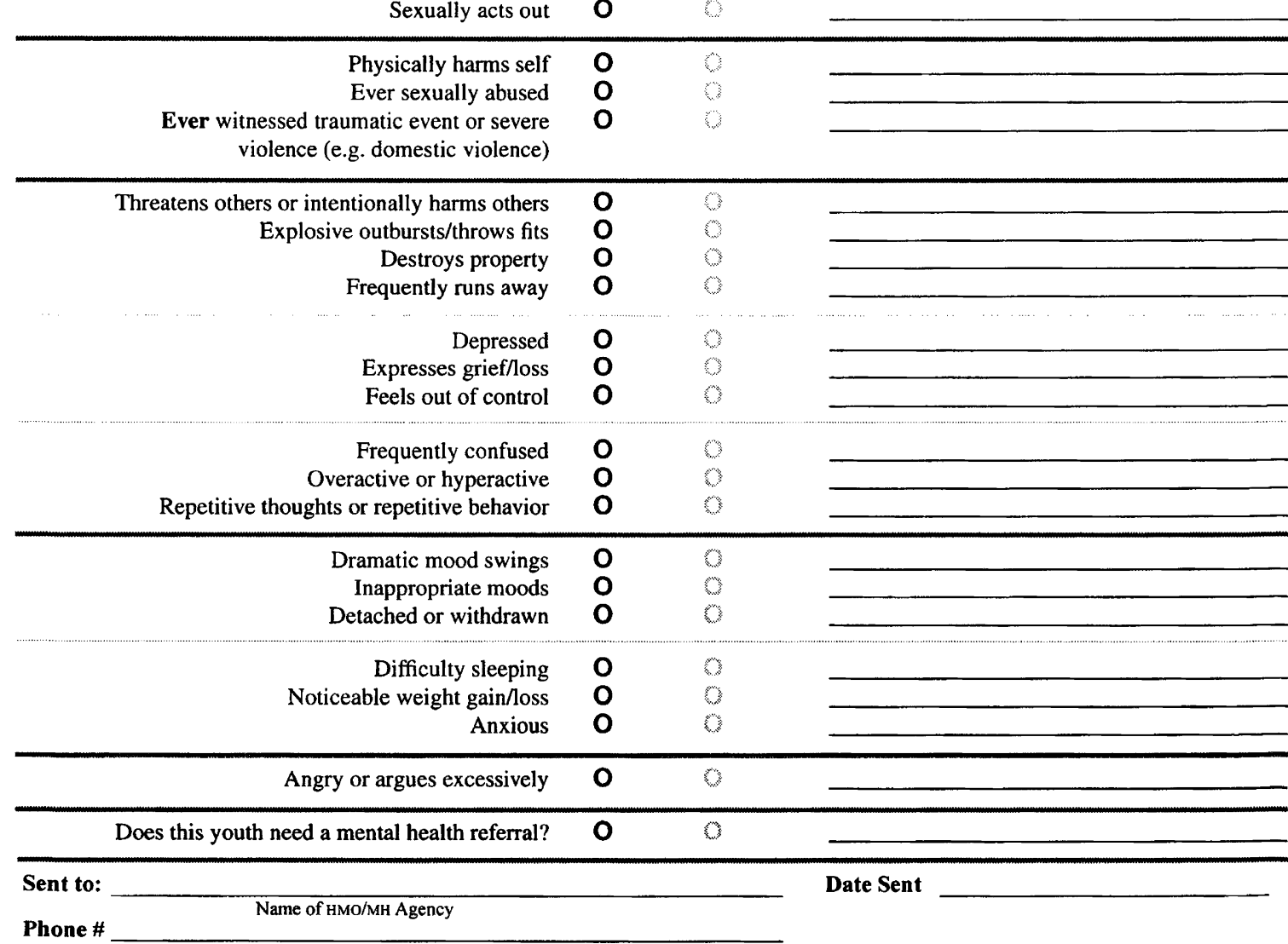




\section{Acknowledgment}

Funding for this research was provided by the Oregon Commission of Children and Families. The views expressed herein are solely those of the author.

\section{References}

Achenbach, T. M. (1997). Manual for the Young Adult Self-Report and Young Adult Behavior Checklist. Burlington: University of Vermont, Department of Psychiatry.
Cocozza, J. J. (1992). Responding to the mental health needs of youth in the juvenile justice system. Seattle, WA: National Coalition for the Mentally Ill in the Criminal Justice System.

Everitt, B. (1980). Cluster analysis. 2nd ed. New York: Halsted Press/Wiley.

Trochim, W. (1989). An introduction to concept mapping for planning and evaluation. Evaluation and Program Planning, 12, 1-16.

Weller, S. C., \& Romney, A. K. (1988). Systematic data collection. Newbury Park, CA: Sage. 